\title{
Acute Abdominal Pain and Paraplegia in a Patient with Chronic Renal Disease: Leriche's Syndrome
}

\author{
Kronik Böbrek Yetmezliği Olan Hastada Akut Karın Ağrısı ve Parapleji: \\ Leriche Sendromu
}

\author{
Aytekin Bayır' , İbrahim Arzıman', Ümit Kaldırım¹, Ali Osman Yıldırım', Mehmet Ali Şahin², Yalçın Bozkurt \\ 'Deparment of Emergency Medicine, Faculty of Medicine, Gülhane Military Medical Academy, Ankara, Turkey \\ 2Deparment of Cardiovasculer Surgery, Faculty of Medicine, Gülhane Military Medical Academy, Ankara, Turkey \\ ${ }^{3}$ Deparment of Radiology, Faculty of Medicine, Gülhane Military Medical Academy, Ankara, Turkey
}

\begin{abstract}
Leriche's syndrome represents an arterial occlusion of the aortic bifurcation with ischaemic symptoms of both legs. A case of Leriche's syndrome as a complication of end stage renal failure has not yet been reported in the litarature. A 50-year-old woman was taken into the emergency service with severe abdominal and leg pain, loss of movement of both legs, and dyspnoea. On physical examination, there was abdominal tenderness, coldness and pallor of both legs, and pulselessness of the upper and lower extremities. No flow was seen in either femoral artery with superficial ultrasonography probe in the emergency department. Dynamic thorax and abdominal computed tomography was planned and total occlusion of the infrarenal level of the abdominal aorta was detected. Within the first hour of the diagnosis of acute thrombosis of the aorta bifurcation, bilateral femoral embolectomy was performed by the Cardiavascular Surgery Clinic. After 1 week, the paitent was discharged without any complication. Chronic renal disease patients, especially those referred to the emergency department with acute complaints, must be evaluated carefully and quickly, primarily for cardiovascular diseases. Principally, infrarenal aortic occlusion must be considered and femoral pulses must be examined in the differential diagnosis for patients presenting with paraplegia and severe pain.
\end{abstract}

Keywords: Leriche's syndrome, chronic renal disease, paraplegia, femoral pulse

Received: 09.04.2012 Accepted: 14.07.2012

\section{ÖZET}

Leriche sendromu aortik bifürkasyonun arteryel oklüzyonuna bağlı her iki alt ekstremitede iskemik semptomların görülmesidir. Literatürde son dönem böbrek yetmezliği olan hastalarda bir komplikasyon olarak Leriche sendromu bildirilen bir olgu mevcut değildir. Elli yaşında bayan hasta giderek artan şiddetli karın ve bacak ağrısı, her iki bacakta güç kaybı ve nefes darlığı şikayeti ile acil servise getirildi. Fizik muayenesinde batında yaygın hassasiyet mevcut, her iki alt ekstremite soğuk-soluk ve bilateral alt ve üst ekstremite nabızlarının açık olmadığı tespit edildi. Acil serviste yapılan ultrasonografide yüzeyel prob ile her iki femoral arterde akım alınamadı. Dinamik toraks ve batın bilgisayarlı tomografi planlandı ve infrarenal düzeyde abdominal aortanın total oklüde olduğu tespit edildi. Acil servise gelişinin birinci saatinde hastaya aort bifurkasyonunda akut trombüs tanısı kondu ve Kardiyovasküler Cerrahi Kliniği'nce acil ameliyata alınan hastaya bilateral femoral embolektomi operasyonu uygulandı. Herhangi bir komplikasyon gelişmeyen hasta bir hafta sonra taburcu edildi. Özellikle acil servislere akut şikayetlerle başvuran kronik böbrek yetmezlikli hastalar öncelikle karidovasküler hastalıklar yönünden dikkatle ve hızla değerlendirilmelidir. Parapleji ile gelen ve şiddetli ağrı tarif eden hastalarda, öncelikle ayırıcı tanıda infrarenal aortik oklüzyon akla gelmeli ve femoral nabazanlar mutlaka kontrol edilmelidir.

Anahtar Kelimeler: Leriche sendromu, kronik böbrek yetmezliği, parapleji, femoral nabız

Geliş Tarihi: 09.04.2012 Kabul Tarihi: 14.07.2012

\section{Giriş}

Otozomal Dominant Polikistik Böbrek Hastalığı (ODPBH) en sık görülen kalıtsal böbrek hastalığıdır. İntrakranial anevrizma, abdominal aort anevrizması (AAA) ve aort diseksiyonu gibi önemli ekstrarenal vasküler klinik olaylarla birlikte karşımıza çıkabilir. ODPBH' nda 3-4. dekatlar arasında böbrek yetmezliği gelişir. Kronik böbrek yetmezliği (KBY) olan hastalarda ölümlerin \%40-50'si kardiyovasküler hastalıklardan (KVH) kaynaklanmaktadır. KBY hastalarında, üremiyle ilişkili olarak çok sayıda hemostatik bozukluk tanımlanmıştır (1). Bu bozukluklar başlıca trombosit foksiyonlarını, koagülasyon sistemini ve fibrinolitik sistemi 
etkiler (1). Hastalığın sadece kendisi değil, bu hastalarda uygulanan hemodiyaliz (HD) ve periton diyalizi (PD) de koagülasyon ve fibrinolitik sistemdeki bozukluğa katkıda bulunur (2). Diyaliz hastalarında fibrinojen düzeylerindeki artış, dislipidemi, sekonder hiperparatiroidizim, koagülasyon sistem aktivitesinin artışı ve fibrinolitik sistemdeki bozukluk KVH için önemli risk faktörleridir ve bütün bu risk faktörlerine bağlı olarak aterotrombotik olay sıklığı da artmıştır (3). Bu ölümcül komplikasyonlar yönünden diyaliz hastaları yakın takip altında izlenmelidir.

Leriche sendromu aortik bifürkasyonun arteryel oklüzyonuna bağlı her iki alt ekstremitede iskemik semptomların görülmesidir (4). Literatürde parapleji ve karın ağrısının eşlik ettiği akut infrarenal aort trombozu ile ilgili yayınlanmış bir olgu yer almamaktadır. Aynı zamanda son dönem böbrek yetmezliği olan hastalarda bir komplikasyon olarak Leriche Sendromu bildirilen bir olgu da mevcut değildir. Akut aortik oklüzyon nedeniyle iskemik semptomların ortaya çıkmasıyla birlikte erken dönemde yapılacak cerrahi ve medikal tedavi hem hastanın mortalitesini engellemiş olacak hem de ekstremite kaybını önleyecektir.

Bu makalede acil servise karın ağrısına eşlik eden bacaklarda ağrı ve güçsüzlük şikayeti olan hastada kısa zamanda tanı ve tedaviye giden yolun öncelikle iyi bir anamnez ve fizik muayeneden geçtiği vurgulanmak istenmiş, Leriche sendromunun klinik özellikleri ile ayırıcı tanısı tartışılmıştır.

\section{Olgu Sunumu}

Elli yaşında bayan hasta giderek artan şiddetli karın ve bacak ağrısı, her iki bacakta güç kaybı ve nefes darlığı şikayeti ile acil servise getirildi. Vital bulguları normal olan hastanın alınan öyküsünden $\mathrm{ODPBH}$ zemininde 25 yıldır KBY tanısı ile takip edildiği, 15 yıl hemodiyaliz ve son 6 aydır periton diyalizi uygulandığı öğrenildi. Fizik muayenesinde batında yaygın hassasiyet mevcut, her iki alt ekstremite soğuk-soluk ve bilateral alt ve üst ekstremite nabızları nonpalpabl olarak tespit edildi. Diğer sistem muayeneleri doğaldı. Acil serviste yapılan ultrasonografide yüzeyel prob ile her iki femoral arterde akım alınamadı, eko probu ile torasik ve üst abdominal aortada diseksiyon tespit edilmedi. Aort distali hastanın ağrısı ve mevcut ODPBH nedeni ile değerlendirilemedi. Dinamik toraks ve batın bilgisayarlı tomografi (BT) planlandı. Infrarenal düzeyde abdominal aorta total oklüde olup, her iki ana ve eksternal iliyak arter lümenlerinin periferal kesimlerinde minimal kontrast dolumu izlendi. İnferior mezenterik arter proksimalde oklüde idi (Resim 1). Acil servise gelişinin birinci saatinde hastaya aort bifukasyonunda akut trombüs tanısı kondu ve heparinize edildi. Hasta onamının alınmasını takiben, Kardiyovasküler Cerrahi Kliniği'nce acil ameliyata alınan hastaya bilateral femoral embolektomi operasyonu uygulandı. Embolektomi işlemi sonrasında her iki femoral arterden bol miktarda trombüs ve üzerine trombüs yapışmış olan aterom plaklarının geldiği görüldü (Resim 2). Embolektomi işlemi sonrasında hastanın her iki femoral arter ve distal nabızlarının açık olduğu saptandı. Herhangi bir komplikasyon gelişmeyen hasta bir hafta sonra taburcu edildi.

\section{Tartışma}

Aortanın akut oklüzyonu çok nadir görülen ancak mortalite ve morbiditesi yüksek olan önemli bir cerrahi acildir (4). Aortoiliyak oklüzif hastalığın iki farklı seyri vardır; akut veya kronik Leriche sendromu (4). Akut Leriche sendromunda bacaklarda iskemik semptomlarla (ağrı, nabızsızlık, parestezi, paralizi, solukluk, soğukluk) birlikte, oklüzyon seviyesine göre intestinal ve/veya renal iskemiye bağlı semptomlar görülür (4). Arteryel embolilerin \%80'i kardiyak kökenlidir ve ekstremitelerde oklüzyona neden olur. Bütün periferik tromboembolilerin \%10-20'si ise kardiyak dışı nedenlerden (aortoiliyak bifürkasyon anevrizması, aort diseksiyonu, aterosklerotik plaklar ve nadiren tümörler) kaynaklanır (5). Illiyak arterlerin ya da aortanın şiddetli aterosklerotik hastalığı infrarenal abdominal aortanın stenozu ya da oklüzyonuna neden olabilir. Leriche sendromu; bilateral kladikasyo, femoral nabazanların alınamaması, alt ekstremitelerde soğukluk-soğukluk, impotans gibi bulgular ile ortaya çıkabilir (6). Bilgimiz dahilinde literatürde KBY ile Leriche sendromu birlikteliği tanımlanmamış olup bu açıdan olgumuz literatürdeki ilk olgudur.

Infrarenal aort ve iliak arterlerin parsiyel oklüzyonunda da bacaklarda güçsüzlük, yürümekle gelen ağrı (kladikasyo), uyuşukluk, erkeklerde impotans, bel ağrısı, nadiren karın ağrısı görülebilir ve bu hastaların tanısı sıklıkla gecikir. Akut total oklüzyonda bu semptomlar ani ve şiddetli başlar, ciddi komplikasyonlar ile seyreder. Akut aortik trombozun erken döneminde meydana gelen anterior spinal kord iskemisine bağlı gevşek (flask) parapleji, arteryel oklüzyonun klasik semptomlarını örterek yanlış tanıya ve zaman kaybına neden olabilir (7). Bu nedenle alt ekstremitede nörolojik defisit ile gelen hastalarda mutlaka periferik nabazanların muayenesi yapılmalıdır (7). Literatürde akut aort trombozuna bağlı parapleji ile ilgili az sayıda bildiri mevcuttur. Surowiec ve ark. (8) akut aortik oklüzyon tespit edilen 33 hastanın 11 'inde başlangıç semptomlarının motor ve duyusal defisit olduğunu gözlemişlerdir. Hastanın tıbbi geçmişi ve mevcut şikayetleri ile ilgili yeterli anamnez alındıktan sonra en kısa zamanda doğru tanı koymak için hızla temel ve kritik muayenelerimizi yapmamız gerekir. Ayırıcı tanıda yer alan aort diseksiyonunda gelişen paraplejinin ağrısız olduğu unutulmamalıdır.

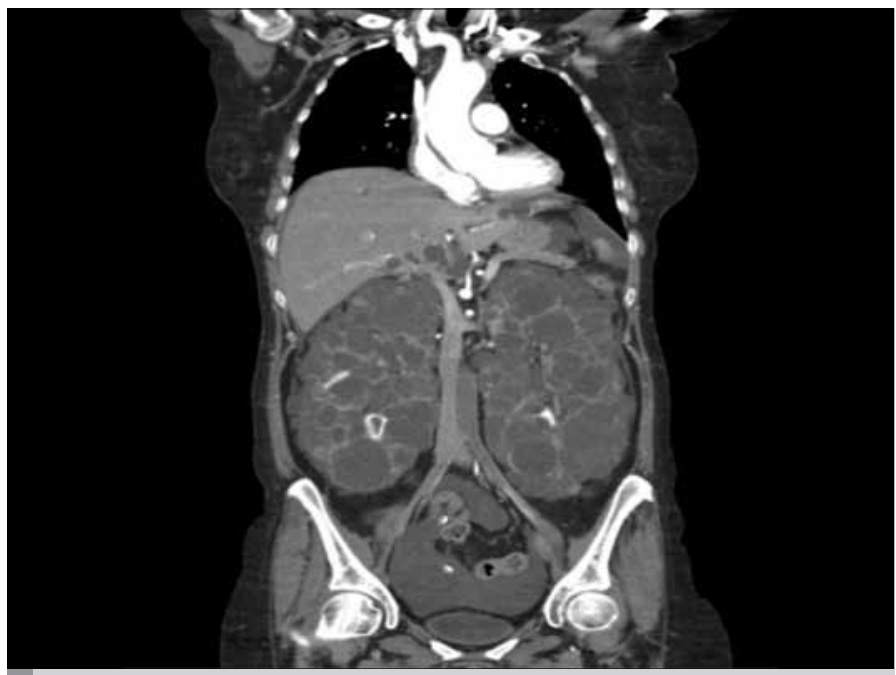

Resim 1. Hastanın Dinamik BT görüntüsü 


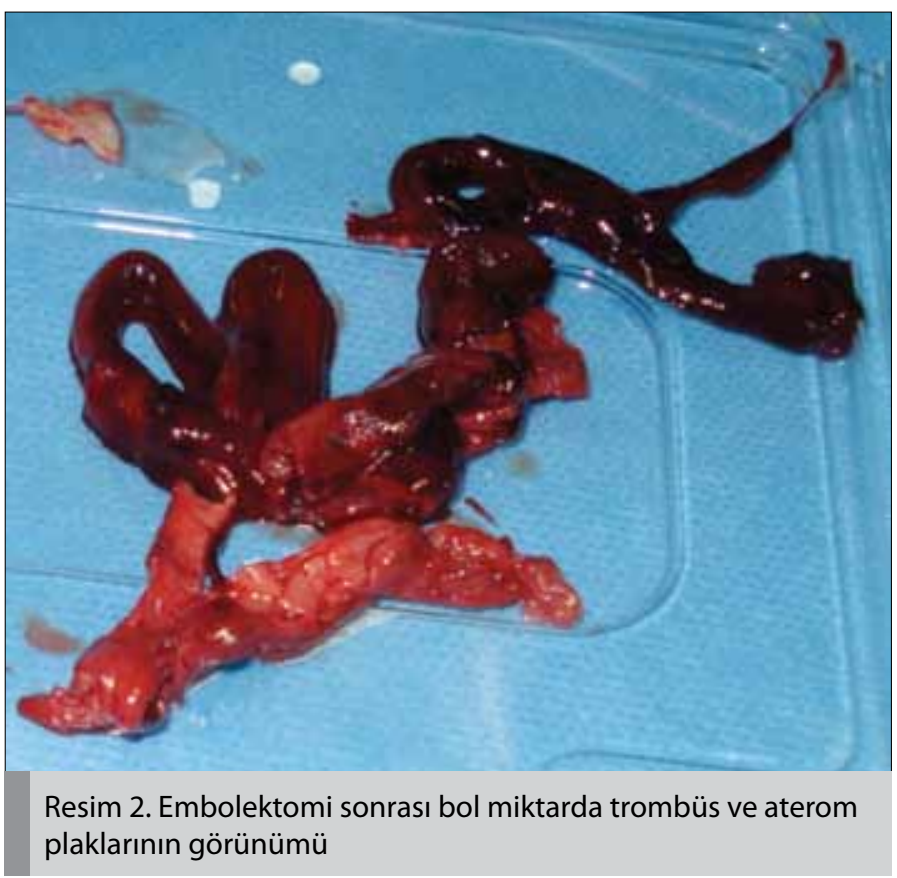

Her ne kadar ODPBH'nda AAA görülse de, sıklıkla meydana gelen komplikasyon aort diseksiyonudur. Anevrizmaya bağlı trombüs gelişimi de genellikle beklenen bir durumdur ancak AAA'nda akut tromboz gelişimi çok nadirdir ve diseksiyon gibi mortalitesi yüksek bir cerrahi acildir (9). ODPBH zemininde gelişen diyaliz bağımlı KBY'nde ise hem hastalığın kendisi hem de diyalize bağlı fizyolojik ve metabolik değişiklikler tromboemboli için zemin hazırlar.

Acil servise karın ağrısına eşlik eden alt ekstremitede güç kaybı ve ağrı şikayeti ile başvuran diyaliz hastalarında artmış tromboembolik risk gözönünde bulundurulmalıdır. Son yıllarda yapılan çalışmalarla KBY olan hastalarda sağlıkı kişilere göre trombotik komplikasyonlar ve aterosklerozun daha sık ve daha erken oluştuğu, özellikle HD ve PD hastalarında hemostatik bozuklukların daha sık görüldüğü bildirilmektedir $(10,11)$. PD hastalarında HD hastalarına göre albumin önemli ölçüde daha düşükken fibrinojen daha yüksek tespit edilmiş dolayısıyla hiperkoagülasyon ve aterotrombotik olaylar için daha riskli oldukları kanıtlanmıştır (1). Hipoalbuminemiye bağlı olarak fibrinojen yanında Lipoprotein(a)'nın hepatik sentezinin arttığı, PD hastalarında doku plazminojen aktivatörü (tPA) ve plazminojen aktivatör inhibitör-1 (PAI-1) seviyelerinin yükseldiği ve aterosklerotik hastalık riskinin arttığı ortaya konmuştur (12)

Hemodiyaliz ve özellikle PD hastalarında mortalite ve morbiditenin azaltılması amacıyla bu hastalar bazı tarama testleri ile takip edilmelidir. BT ile PD bağlantılı pek çok komplikasyon tarif edilmiştir (13). HD sonrası artmış serum Ca ile ilişkili olarak aortik kalsifikasyon gelişmektedir (14). Abdominal aort kalsifikasyonu varlığı KVH ve mortaliteyi göstermede prognostik öneme sahiptir. BT yerine ucuz ve kolay bir metod olan lateral lomber radiografi ile diyaliz hastaları değelendirilebilir (15). Lateral lomber grafi rutin klinik uygulamada prognostik belirteç olarak kullanılabilir (15). Özellikle diyabetik KBY'li hastalarda da Aortik Pulse Wave Velocity ölçümleri ile aortik sertlik değerlendirilebilir (16). Artmış aortik sertlik, yüksek KVH ve mortalite ile ilişkilidir (16). KBY'li hastalarda erken prognostik belirteçler ile uzun yaşam süreleri sağlanabilir.

\section{Sonuç}

Özellikle acil servislere akut şikayetlerle başvuran KBY'li hastalar öncelikle KVH yönünden dikkatle ve hızla değerlendirilmelidir. Parapleji ile gelen ve şiddetli ağrı tarif eden hastalarda, öncelikle ayırıcı tanıda infrarenal aortik oklüzyon akla gelmeli ve femoral nabazanlar kontrol edilmelidir.

Ön tanımızı doğrulamak, kesin tanı ve erken tedavi için zaman kazanmak istiyorsak acil serviste ultrasonografi ile distal aorta ve femoral arteri değerlendirebiliriz. İnfrarenal aortik oklüzyonun kesin tanısı ve diğer intraabdominal patolojilerin ekartasyonu için hastalar BT anjiografi ile değerlendirilmelidir ancak bizi doğru tanıya götürecek olan her zaman iyi bir anamnez ve detaylı fizik muayenedir.

\section{Conflict of Interest}

No conflict of interest was declared by the authors.

Peer-review: Externally peer-reviewed.

\section{Author Contributions}

Concept - A.B., U.K.; Design - A.B., I.A.; Supervision - A.B., I.A.; Funding A.B.; Materials - A.B., MA.S.; Data Collection and/or Processing - A.B., I.A., U.K., A.O.Y., Y.B.; Analysis and/or Interpretation - U.K., A.O.Y., M.A.S.; Literature Review - A.B., I.A., Y.B.; Writer - A.B.; Critical Review - A.B., M.A.S.

\section{Çıkar Çatışması}

Yazarlar herhangi bir çıkar çatışması bildirmemişlerdir.

Hakem değerlendirmesi: Dış bağımsız.

\section{Yazar Katkıları}

Fikir - A.B., U.K.; Tasarım - A.B., I.A.; Denetleme - A.B., I.A.; Kaynaklar - A.B.; Malzemeler - A.B., MA.S.; Veri toplanması ve/veya işlemesi - A.B., I.A., U.K., A.O.Y., Y.B.; Analiz ve/veya yorum - U.K., A.O.Y., M.A.S.; Literatür taraması A.B., I.A., Y.B.; Yazıyı yazan - A.B.; Eleştirel İnceleme - A.B., M.A.S.

\section{Kaynaklar}

1. Malyszko J, Malyszko JS, Mysliwiec M. Comparison of hemostatic disturbances between patients on CAPD and patients on hemodialysis. Perit Dial Int 2001; 21: 158-65.

2. Sönmez ÖU. Hemodiyaliz tedavisi gören diyabetik ve nondiyabetik hastalarda fibrinolitik sistem aktivitesinin araştırıması: Uzmanlık Tezi, 2008; Haseki Eğitim ve Araştırma Hastanesi, İstanbul.

3. Hryszko T, Malyszko J, Malyszko JS, Brzosko S, Mysliwiec M. Patients on peritoneal dialysis but not on hemodialysis have elevated concentration and activity thrombin activable fibrinolysis inhibitor. Thromb Res 2001; 104: 233-8. [CrossRef]

4. Zankl AR, Blessing E, Volz HC, Krumsdorf U, Katus HA, Andrassy M. Neurological symptoms in acute Leriche's syndrom. Clin Res Cardiol 2010; 99: 459-62. [CrossRef]

5. Elbardissi AW, Dearani JA, Daly RC, Mullany CJ, Orszulak TA, Puga FJ, et al. Embolic potential of cardiac tumors and outcome after resection: a case-control study. Stroke 2009; 40: 156-62. [CrossRef] 
6. LeeWJ, Cheng YZ, Lin HJ. Leriche syndrome. Int J Emerg Med 2008; 1:223. [CrossRef]

7. Triantafyllopoulos GK, Athanassacopoulos M, Maltezos C, Pneumaticos SG. Acute infrarenal aortic thrombosis presenting with flaccid paraplegia. Spine 2011; 36: 1042-5. [CrossRef]

8. Surowiec SM, Isiklar H, Sreeram S, Weiss VJ, Lumsden AB. Acute occlusion of the abdominal aorta. Am J Surg 1998; 176: 193-7. [CrossRef]

9. El-Kayali A, Al-Salman M. Unusual presentation of acute bilateral lower limb ischemia: Thrombosis of abdominal aortic aneurysm-case report . Annals of Saudi Medicine 2001; 21:5-6.

10. Cheung AK, Sarnak MJ, Yan G, Dwyer JT, Heyka RJ, Rocco MV, et al. Atherosclerotic cardiovascular disease risk in chronic hemodialysis patients. Kidney Int 2000; 58: 353-62. [CrossRef]

11. Kobayashi M, Yorioka N, Yamakido M. Hipercoagulability and secondary hyperfibrinolysis may be related to abnormal lipid metabolism in patients treated with continuous ambulatory peritoneal dialysis. Nephron 1997; 76: 56-61. [CrossRef]
12. Kim KJ, Yang WS, Kim SB, Lee SK, Park JS. Fibrinogen and fibrinolytic activity in CAPD patients with atherosclerosis and it's correlation with serum albumin. Perit Dial Int 1997; 17: 157-61.

13. Cakir B, Kirbaş I, Cevik B, Ulu EM, Bayrak A, Coşkun M. Complications of continuous ambulatory peritoneal dialysis: evaluation with $C T$. Diagn Interv Radiol 2008; 14: 212-20.

14. Yamada K, Fujimoto S, Nishiura R, Komatsu H, Tatsumoto M, Sato Y, et al. Risk factors of the progression of abdominal aortic calcification in patients on chronic haemodialysis. Nephrol Dial Transplant 2007; 22: 2032-7. [CrossRef]

15. Honkanen E, Kauppila L, Wikström B, Rensma PL, Krzesinski JM, Aasarod $\mathrm{K}$, et al. Abdominal aortic calcification in dialysis patients: Results of the CORD study. Nephrol Dial Transplant 2008; 23: 4009-15. [CrossRef]

16. Shoji T, Emoto M, Shinohara K, Kakiya R, Tsujimoto Y, Kishimoto H, et al. Diabetes mellitus, aortic stiffness, and cardiovascular mortality in endstage renal disease. J Am Soc Nephrol 2001; 12: 2117-24. 